\title{
Yanzhong Huang, Toxic Politics: China's Environmental Health Crisis and its Challenge to the Chinese State
}

\author{
(Cambridge et al.: Cambridge University Press, 2020), 264p; \$24.99 \\ paperback
}

\section{Maria Bondes ${ }^{1}$}

Accepted: 13 December 2021 / Published online: 11 January 2022

(c) The Author(s) 2022

How successful has China been in addressing its environmental crisis? And what does this tell us about the state of the Chinese state and the viability of the so-called China model? Yanzhong Huang addresses these questions through an in-depth investigation of China's environmental health governance. By examining the partystate's capacity to respond effectively to the deepening environmental health crisis, regarded by Huang as "perhaps the most important litmus test for the resilience of the Chinese state" (p. 18), he seeks to evaluate the crisis management skills and governance performance of China's authoritarian political system. Huang shows that while impressive progress has been made in reducing pollution and tackling environmental health under Xi Jinping, a closer investigation finds only mixed results and numerous adverse effects that highlight the "constraints and flaws of China's authoritarian governance model" (p.183) - most importantly the fragility of a regime that bases its legitimacy largely on performance, the lack of institutionalized public participation, and policy implementation that remains "lopsided, non-synergistic, and based on coercion" (p. 191). Huang's analysis challenges "the widely held view that China is winning the environmental health battle" (p. 3) and reveals what he calls an "authoritarian system that is remarkably resilient but fundamentally flawed" (p. 192).

Through five main chapters and a multi-disciplinary approach, Huang takes detailed account of the effects of China's environmental pollution and carefully assesses the effectiveness of China's state response. The first part of the book highlights the enormous extent and complexity of China's air, water and soil pollution and its detrimental consequences not only for human health but also for China's national economy, sociopolitical stability and foreign policy. The second part of the book evaluates the government's environmental health-related policy efforts. Huang

Maria Bondes

maria.bondes@fu-berlin.de

1 Institute of Chinese Studies, Freie Universität Berlin, Berlin, Germany 
outlines the evolution of environmental health policy as a "long and windy tale" (p.87) from the emergence of environmental awareness in the 1960s to becoming a top policy priority under Xi Jinping, and identifies a number of limitations and dilemmas in China's policymaking that impede effective implementation, including a lack of convergence of science and policy, state-society information asymmetry, delays in creating a health-related environmental policy, and a continuing conflict between development and environmental health.

Turning to the implementation stage, Huang assesses the new policy instruments and governance mechanisms introduced under $\mathrm{Xi}$, including more quantifiable and transparent policy targets, engaging the public in policy implementation, centralized environmental monitoring, and policy enforcement supervision. While these demonstrate a recognition of existing problems and "wholesale commitment to the cause" (p.188), Huang contends that many of the inherent policy implementation challenges - such as upward accountability, lack of public participation, conflict between functional departments and territorial governments, and the central state's inability to effectively monitor and evaluate bureaucratic performance - remain untouched and continue to hamper policy effectiveness. Rather than rendering the environmental governance regime more flexible and effective, Huang argues that recent reforms have not changed the "impromptu, nonparticipatory, unaccountable, and mobilizational policy process, which often leads to undesirable and unintended policy outcomes" (p. 184), and are thus "no more than an effort to tighten authoritarian control" (pp.191-192). Getting an effective handle on the environmental health crisis would, however, require "profound changes in state-market relations, bureaucratic power structure, and state-society relations" (p. 15). Huang thus comes to similar conclusions as Li Yifei and Judith Shapiro in their book China goes green: Coercive environmentalism for a troubled planet (2020), which came out around a similar time.

One might wonder whether Huang's arguments about the flaws in China's environmental governance model are really new. Most of the implementation challenges are well-known in the literature and similar points have also been raised with regard to the recent centralization efforts and governance mechanisms introduced under $\mathrm{Xi}$. A more thorough engagement with the existing literature on China's environmental governance and recent reforms in the second part of the book could have underpinned Huang's arguments and substantiated some of the sections that naturally have to remain on the surface given the wealth of issues covered in the book. However, Huang's multi-disciplinary approach and the comprehensiveness and detail in which he assesses the extent and effects of China's environmental health crisis and recent policy efforts is truly new and complements Li and Shapiro's macro-level approach. Moreover, Huang gives clear answers to two important and very timely questions. First, with regard to the resilience of the Chinese party-state, Huang shows that China's handling of the environmental health crisis has demonstrated the regime's remarkable resilience. This resilience is, however, not based on innovation and adaptation, but on the strengthening of authoritarian control and a "mobilizational state" (pp.190) that will continue to be haunted by the environmental crisis unless fundamental change occurs, including more participatory forms of governance. Second, amid ongoing discussions about the viability of "environmental authoritarianism" as 
approach for solving the global environmental crisis, Huang highlights the flaws and weaknesses in Xi's authoritarian style of governance. Together with the enormous extent of environmental degradation in China, this calls in question the superiority of the so-called China model.

I would highly recommend this book for China scholars and those interested in authoritarian governance approaches and recent developments under $\mathrm{Xi}$, both in the environmental realm and beyond. The book is also of great value for classes on Chinese politics, authoritarianism and environmental politics to show the potentials and limitations of authoritarian models of governance and for a clear assessment of the recent governance reforms under Xi Jinping.

Funding Open Access funding enabled and organized by Projekt DEAL.

\section{Declarations}

Conflict of Interest There are no conflicts of interest reported by the author.

Open Access This article is licensed under a Creative Commons Attribution 4.0 International License, which permits use, sharing, adaptation, distribution and reproduction in any medium or format, as long as you give appropriate credit to the original author(s) and the source, provide a link to the Creative Commons licence, and indicate if changes were made. The images or other third party material in this article are included in the article's Creative Commons licence, unless indicated otherwise in a credit line to the material. If material is not included in the article's Creative Commons licence and your intended use is not permitted by statutory regulation or exceeds the permitted use, you will need to obtain permission directly from the copyright holder. To view a copy of this licence, visit http://creativecommons.org/licen ses/by/4.0/.

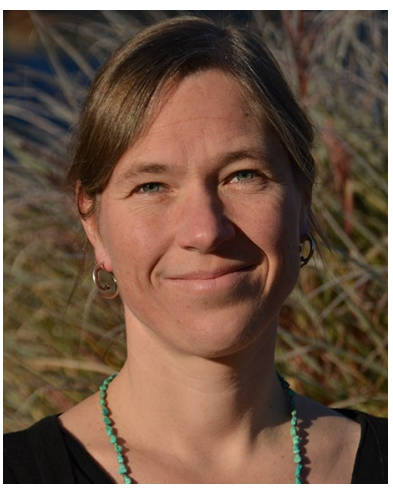

Maria Bondes is a guest lecturer at the Institute of Chinese Studies, Freie Universität Berlin. Her research centers on state-society relations, contentious politics and environmental politics in China with a focus on environmental contention. In her recent book "Chinese Environmental Contention: Linking Up against Waste Incineration" (Amsterdam University Press) she investigates the network of contention that has emerged in China's anti-incineration realm. 